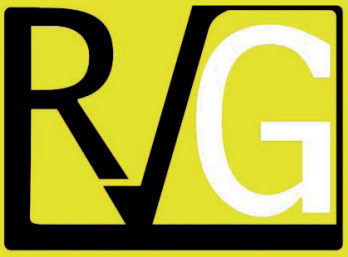

Julio - Septiembre, 2021

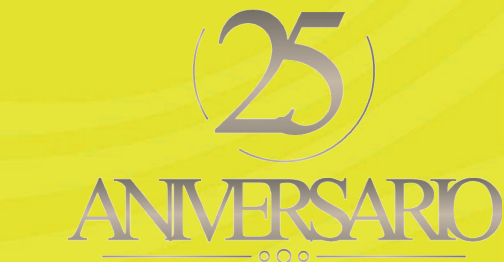

ANMERSARO
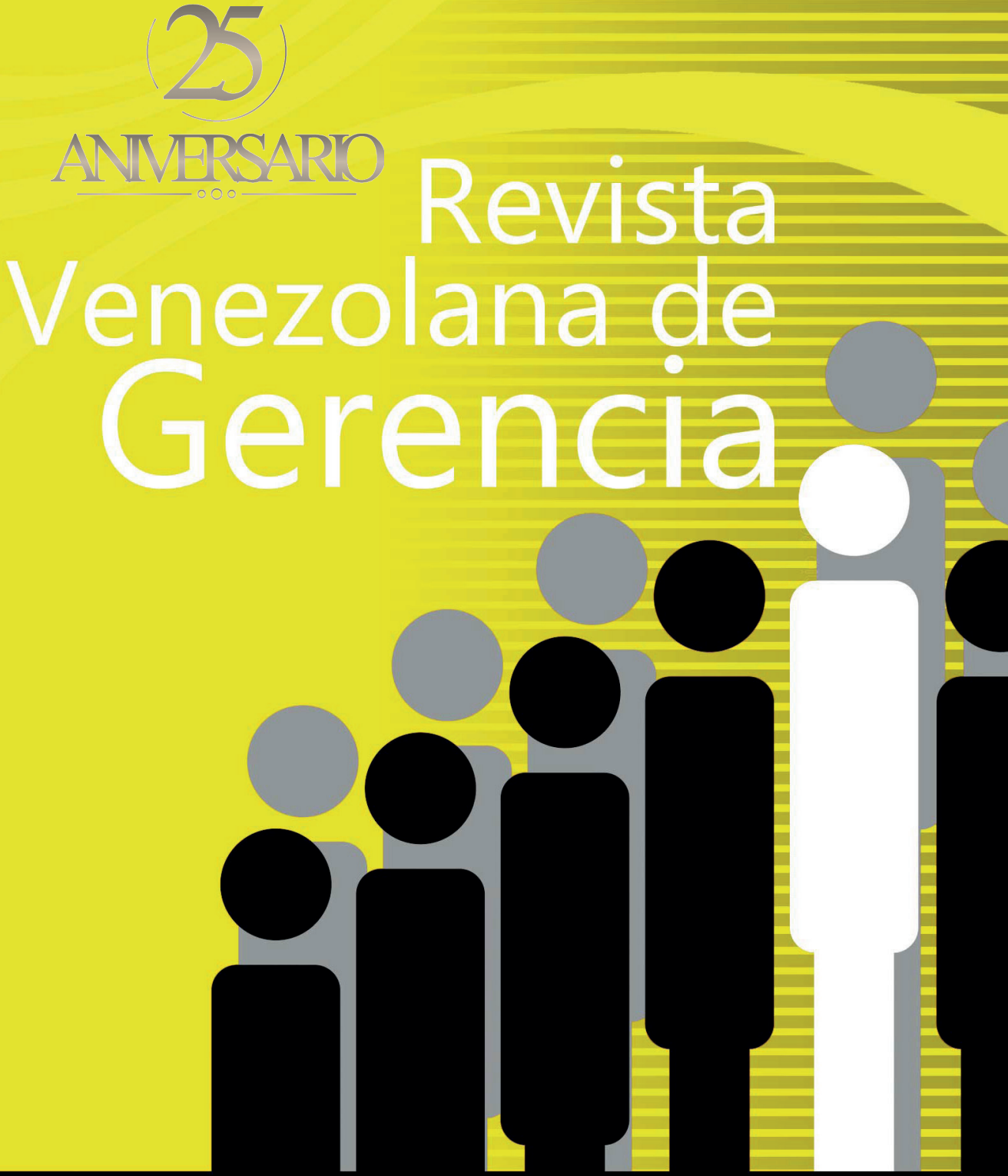

UNIVERSIDAD DEL ZULIA (LUZ)

Facultad de Ciencias Económicas y Sociales Centro de Estudios de la Empresa

ISSN 1315-99

Esta obra está bajo una licencia de Creative Comm Reconocimiento-NoComercial-Compartirlgual 3.0 Unpo http://creativecommons.org/licenses/by-nc-sa/3.0/deed.es 
COMO CITAR: Flores Arocutipa, J. P., Tarmeño Bernuy, L. E., Cruz Montero, J. M., y Franco Medina, J. L. (2021). Discusión de la noción de comuna: Recorrido teórico-documental. Revista Venezolana de Gerencia (RVG), 26(95), 669-682. https://doi.org/10.52080/
Universidad del Zulia (LUZ)

Revista Venezolana de Gerencia (RVG)

Año 26 No. 95 Julio-Septiembre 2021, 669-682

ISSN 1315-9984 / e-ISSN 2477-9423

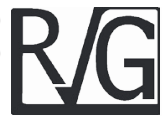

\title{
Discusión de la noción de comuna: Recorrido teórico-documental
}

\author{
Flores Arocutipa, Javier Pedro* \\ Tarmeño Bernuy, Luis Edgar** \\ Cruz Montero, Juana María*** \\ Franco Medina, Jorge Lázaro****
}

\section{Resumen}

La presente investigación recorre el origen y el uso de la noción de comuna en las ciencias sociales. El objetivo de la misma es analizar las distintas perspectivas de la comuna desde una mirada teórica documental. Se parte del estudio de la primera aparición del término haciendo referencia a las organizaciones de la Italia medieval, recorriendo la experiencia de la Comuna de París, las experiencias de la revolución China y las más recientes expresiones y usos en Venezuela. La presente investigación es de tipo teórico documental. Las reflexiones sobre el término arrojan que existen dos grandes nociones de esta categoría, por un lado, referencia una forma local de organización político-administrativa del territorio, por otro, da lugar a formas de resistencia anti-feudal, en su momento, y anti-capitalistas en la actualidad.

Palabras clave: Comunas; organización política; resistencia.

* Doctor en Administración, Dr. en Economía, Dr. en Ciencias Sociales, Dr. en Educación, Mag. Gestión Pública, Mag. Tecnología Educativa. Perú. Filiación: Universidad Nacional de San Agustín de Arequipa. Email: jfloresaro@unsa.edu.pe ORCID: https://orcid.org/0000-0003-0784-4153

** Magister en Administración de la Educación, MBAAdministración de Empresas, Licenciado en Ciencias de la Comunicación. Docente investigador y coordinador académico. Filiación: Universidad Tecnológica del Perú. Email: Itarmeno@utp.edu.pe ORCID: https://orcid.org/0000-0001-7511-5273

*** Doctora en Educación, Licenciada en Educación Inicial. Filiación: Universidad César Vallejo. Email: jcruzmo@ucv.edu.pe ORCID: https://orcid.org/0000-0002-7772-6681

**** Doctor en Administración, Maestro en Docencia Universitaria, Ingeniero Industrial. Filiación: Universidad Nacional de Cañete. Email: jfranco@undc.edu.pe ORCID: https://orcid.org/0000-0002-3668-5174 


\title{
Discussion of the notion of commune: Theoretical-documentary tour
}

\begin{abstract}
This research covers the origin and use of the notion of commune in the social sciences. Its objective is to analyze the different perspectives of the commune from a documentary theoretical perspective. It starts from the study of the first appearance of the term referring to the organizations of medieval Italy, going through the experience of the Paris Commune, the experiences of the Chinese revolution and the most recent expressions and uses in Venezuela. The present investigation is of a theoretical documentary type. The reflections on the term show that there are two great notions of this category, on the one hand, it refers to a local form of political-administrative organization of the territory, on the other, it gives rise to forms of anti-feudal resistance, at the time, and anti -capitalists today.
\end{abstract}

Keywords: Communes; political organization; resistance.

\section{Introducción}

Cuando se habla de comuna es ampliamente entendido que este término se refiere a un conjunto de personas que viven en comunidad, los lazos pueden ser de diversa naturaleza. En un sentido, las reglas de convivencia pueden estar al margen de la sociedad organizada (caso las comunas hippies en Estados Unidos y Europa, las comunas zapatistas en México o comunas anarquistas); mientras que por otro lado, comuna hace referencia a formas de organización social y económica que se basa en la propiedad colectiva (caso comunas en Venezuela o China).

Sin embargo, en un sentido más general, una comuna es una subdivisión político-administrativa de una zona rural o urbana correspondiente a instancias de administración local. En muchos países el nombre comuna se refiere a la unidad administrativa menor, local o básica, algunos de estos son Alemania,
Argentina, Bélgica, Perú, Chile, Colombia, Ecuador, Francia, Venezuela, entre otros.

Analizar y evaluar la noción de comuna no es tarea fácil. Cualquier abordaje de este término está condicionado por la lupa políticaideológica que ha acompañado casi desde su origen las interpretaciones que se difunden alrededor de este concepto.

En el presente trabajo se hace un recorrido en los distintos usos de este concepto y se busca analizar las distintas perspectivas de la comuna desde una mirada teórica documental. La presente investigación es de tipo teórico documental.

El origen del término es de las comunas urbanas de la Edad Media, en donde se le conocía de ese modo a las ciudades italianas independientes del señor feudal. Sin embargo, la forma administrativa actual de las comunas corresponde a la comuna en Francia, experimento que dio lugar al nacimiento 
de las funciones competentes a la subdivisión menor en la cual se asocian los departamentos y otras agrupaciones administrativas superiores.

\section{Nacimiento del término}

\section{En el recorrido teórico sobre las comunas es imprescindible} conceptualizar esta noción y sus usos a través del tiempo, para ello, se indagó en lo propuesto por Bobbio y Mateucci(1985) en su Diccionario de política. Este término surge en la Italia Medieval. La comuna italiana era la comunidad citadina que representaba la forma de organización social "jamás producida". Algunas de sus características han perdurado hasta la actualidad. En el lenguaje corriente se concibe a la comuna, aunque en principio diferenciada de la ciudad, casi cómo sinónimos; aunque es más frecuente concebir a la comuna como el instrumento de gestión administrativa de la segunda. Se puede decir, que la noción de comuna es fundamentalmente europea, de su literatura y de sus ciencias político-administrativas.

Aunque la comuna italiana de ese contexto se diferenciaba de otras comunas europeas, particularmente en la relación ciudad y campo, no es sólo el carácter rural lo que la distingue, por ejemplo, algunas de sus funciones no se encuentran plenamente en las comunas del resto de Europa. Estas funciones podemos resumirlas en: a) la creación de nuevas estructuras de poderes políticos urbanos; b) la reorganización del territorio provincial (comitatus); y c) la creación de un nuevo sistema productivo capaz de sostener un desarrollo intensísimo y auto-reproducirse.

La autoridad política en la Italia a partir del siglo $X$ radicaba en el Conde, quien se ubicaba fuera de la ciudad.
Dentro de la ciudad fungía el vizconde. Sin embargo, dentro de las ciudades en períodos de paz había otro poder capaz de establecer autoridad, se trata del obispo, quienes nunca abandonaban la ciudad. En esta estructura fue donde se estableció a partir del siglo $\mathrm{X}$, el proceso genético de la communitas citadina.

Con la era Otoniana comenzó el proceso de "comitatización" del episcopus sobre una sola ciudad. El obispo se convertía así en el "conde" de la ciudad, en el representante local del poder imperial $y$, en consecuencia, en titular del poder estatal sobre el centro urbano, contraponiéndose al antiguo conde-vizconde. La ciudad se convertía entonces a partir de la segunda mitad del siglo $X$ en una especie de distrito autónomo separado administrativa y políticamente del territorio provincial.

A finales del siglo $\mathrm{XI}$ el rígido sistema feudal se desmoronaba, por lo que se buscaban formas de organización menos individualistas y verticales. En este contexto nace la comuna citadina como fenómeno feudal, aunque nutrida de una lógica anti-feudal (Bobbio y Mateucci, 1985). Se consolidó de esta manera un sistema asociacionista en los diversos centros citadinos imperiales, lo que permitió que las múltiples fuerzas sociales se agregaran a la burguesía superando la fragmentación organizativa y favoreciendo su propio poder de ruptura ante la propiedad eclesiástica y militar.

Esta transición de la comuna entre hechos feudales a hechos citadinos tuvo su repercusión en la estructura social y la organización del poder cuando los grupos feudales se unieron a los núcleos nacientes de la burguesía comercial urbana (los notarios, los jueces, los mercaderes y los cambistas), quienes se asociaban con los grupos feudales que 
intentaban tener o tenían el control de la ciudad. De esta manera, expulsando o englobando al representante episcopal, la comuna se establecía como sustituta del gobierno episcopal o del conde mismo. Esto garantizaba a la comuna el control de la ciudad, resultando en ella la unión entre capital móvil y capital inmobiliario para sostener dicho control (Bobbio y Mateucci, 1985).

En sus inicios esta organización comunal adoleció de escasa cohesión interna entre los diversos grupos que la componen. Esta ausencia de cohesión se hizo evidente en las formas organizativas que produjo la comuna, como la asamblea de todos sus miembros, o el colegio consular, grupo dirigente constituido por tantos miembros como núcleos iban apareciendo en la communitas. Al hablar de colegio consular o communitas estamos hablando de aristocracia o feudalismo, el fenómeno se conoce como "feudalismo comunal". La ciudad mantuvo las formas feudales fuera de la ciudad, en el campo, siempre que no interfiriera con su desarrollo, al contrario, les permitían crecer como organización. De hecho, el mundo rural, sujeto a la comuna, debió servir a la ciudad como área de abastecimiento de bienes y de mano de obra de bajo costo y al mismo tiempo como mercado para todas las mercancías citadinas que no estaban destinadas al consumo urbano o a la exportación (Bobbio y Mateucci, 1985).

La burguesía empresarial, mercantil y comercial citadina era de crecimiento ascendente. Esta burguesía colocaba su mirada en la posibilidad de un comercio mayor de características europeas e incluso mundiales, por tanto, los controles regionales eran algo que deseaban saltar. Estos objetivos ambiciosos de la burguesía de entonces entraban en conflicto con las limitaciones del restringido gobierno citadino. En cada centro de poder feudal-citadino en donde se formó una poderosa burguesía empresarial, se encontraba la oposición de la monarquía pretendiendo bloquear su desarrollo, esta oposición se resolvió con la introducción del régimen podestá ${ }^{1}$ a finales del siglo XII sin destruir el pacto comunal.

El podestá tenía que ser ejercido por una persona que no perteneciera a la ciudad, evitando su implicación personal en las controversias, garantizando imparcialidad. Éste gobernaba ejerciendo los poderes ejecutivos, administrativos, judiciales y de policía. El hecho de que este cargo se convirtiera en un oficio profesional que cambiaba a menudo de personal contribuyó a que las leyes se hicieran homogéneas entre distintas ciudades por donde los mismos postestaes habían gobernado. Sin embargo, los burgueses en su rápido desarrollo obligaban a romper el pacto político con los grupos feudales citadinos, acentuándose este proceso durante el siglo XIII.

\section{La comuna como espacio de resistencia}

Como se ha planteado, la comuna nace en Italia y con manifestaciones similares en Francia y Alemania, como asociación de comerciantes y pequeños empresarios que, no debiendo realizar su propia defensa, asegurada por el poder dinástico y señorial, se ve

1 En la actualidad el término Podestá se utiliza como sinónimo de juez o gobernador, resignificado a partir de la experiencia política de la Italia fascista de inicios del siglo XX. 
obligada a establecer para sí misma reglas de conducta comercial, de tutela jurisdiccional, de mutuo socorro, de respeto común. También aquí se presenta una asociación horizontal, abierta, que se modifica a sí misma, a diferencia del régimen jerárquico rígido, vertical y establecido hasta ahí por la estructura agrario-feudal prevaleciente.

Fuera de Italia, la comuna fue siempre una experiencia particular dentro de la ciudad, que difícilmente lograba asumir la dirección de todos los núcleos citadinos viejos. Sin embargo, en Italia podemos decir que la comuna es una organización privada de los grupos burgueses alejado de la ciudad, que le arranca al señor eclesiástico o laico un preciso estatus privilegiado, que obtiene y amplía progresivamente su propia autonomía y su correspondiente autogestión, pero que casi nunca logra librar de manera sustancial a toda la ciudad del control feudal, al que también se ve sometida ella misma (Bobbio y Mateucci, 1985).

El campo para los comunalistas es un lugar de intercambio, una zona de recolección de mercancías y de ventas de manufacturas, pero no es nunca una realidad sometida política y jerárquicamente a ella misma. Por tanto, la comuna no logra salir nunca de su realidad señorial al tiempo que no sufre transformaciones institucionales fuera de un cierto nivel.

En este sentido, Marx y Engels (1848) en su Manifiesto del Partido Comunista explican al respecto como la burguesía forma en la comuna una asociación autónoma y armada para la defensa de sus intereses. Éstas toman diversas formas, en unos sitios se organiza en repúblicas municipales independientes; en otros forma el tercer estado tributario de las monarquías; en la época de la manufactura fueron el contrapeso de la nobleza dentro de la monarquía feudal o absoluta. Por último, es implantada la gran industria y así se han abierto los cauces del mercado mundial, se conquista la hegemonía política y crea el moderno Estado representativo. En estas reflexiones podemos notar que los autores permiten un uso flexible de la noción de comuna, a partir de las múltiples formas organizativas que la burguesía adoptó y continúa adaptando, aunque en la actualidad el término comuna hace mayor referencia a formas organizativas de resistencia al capitalismo ${ }^{2}$, que de igual modo adaptan y pueden adaptar múltiples formas.

En ese sentido, las comunas que lograron mayor nivel de autonomía con respecto al control feudal y Estatal son las pertenecientes a las llamadas "ciudades libres" en la Edad Moderna. Éstas se tratan de excepciones no muy numerosas, a diferencia de Italia, en donde las comunas si alcanzaron un nivel de fragmentación administrativa que dificultaron luego el reordenamiento de amplia envergadura regional y estatal.

Es a partir de la llamada Comuna de París donde el marxismo toma la noción de comunas para exportarla al resto del mundo, y a la propia Europa, como forma de organización

\footnotetext{
2 Esta noción de comunas como formas de resistencia al capitalismo es herencia de la comuna francesa y ahora revivida en las comunas venezolanas. Sin embargo, en la propia Francia contemporánea, como en algunos países latinoamericanos la noción de comuna hace vida como formas administrativas de poblados sin representar formas de resistencia.
} 
del proletariado contra el capitalismo. El marxismo libra a la comuna de su carácter burgués para convertirla en una noción del proletariado. En esta dirección, podemos revisar algunos de los usos que desde las experiencias autoproclamadas anti-capitalistas se le ha dado a la noción de comuna.

Marx en su obra "La guerra civil en Francia" nos dice refiriéndose a la Comuna de París que "la antítesis directa del Imperio era la Comuna" (Marx, 2012:22), siendo la Revolución de Febrero el anhelo de una República que acabase con la forma monárquica de dominación de clase y la propia dominación de clase, "la comuna era la forma positiva de esta República" (Marx, 2012:22), a diferencia del capitalismo que es la forma negativa de esa República post-monárquica.

La comuna de París fue un breve movimiento insurrecional provocado por la milicia ciudadana, la Guardia Nacional Francesa, que gobernó París desde el 18 de marzo hasta el 28 de mayo de 1871 , tras la derrota y derrumbe del gobierno imperial de Napoleón III en la guerra franco-prusiana, y la proclamación imperial de Guillermo I de Alemania. El término comuna, del francés commune, designa ayuntamiento en francés.

Para garantizar su durabilidad, una de las primeras medidas tomadas por la Comuna de París en 1871 fue suprimir el ejército y la policía, los cuales eran elementos de control físico del antiguo régimen. Así mismo, dice el autor que la comuna "tomó medidas inmediatamente para destruir la fuerza espiritual de la represión: el "poder de los curas", decretando la separación de la Iglesia del Estado y la expropiación de todas las iglesias" (Marx, 2012:23). De este modo, por "fuerza espiritual" podemos interpretar los aparatos de control ideológico del estado, a través de los cuales se interviene las identidades.

Sobre la organización y funcionamiento de la Comuna parisina, el autor destaca que ésta "no había de ser un organismo parlamentario, sino una corporación de trabajo, ejecutiva y legislativa al mismo tiempo" (Marx, 2012:23), así mismo, "todos los delegados serían revocables en todo momento y se hallarían obligados por el mandat impératif (instrucciones formales) de sus electores" (Marx, 2012: 24).

La comuna ha sido señalada de fraccionadora (Montesquieu y los Girondinos), sin embargo, en su defensa Marx la considera una forma política perfectamente flexible, a diferencia de las anteriores las cuales eran fundamentalmente represivas. Sin embargo, el propio Marx expone en el texto en consideración del carácter "emancipador" de la comuna de la clase obrera parisina:

"iLa Comuna, exclaman, pretende abolir la propiedad, base de toda civilización! Sí, caballeros, la Comuna pretendía abolir esa propiedad de clase que convierte el trabajo de muchos en la riqueza de unos pocos. La Comuna aspiraba a la expropiación de los expropiadores. Quería convertir la propiedad individual en una realidad, transformando los medios de producción, la tierra y el capital, que hoy son fundamentalmente medios de esclavización y de explotación del trabajo, en simples instrumentos de trabajo libre y asociado. ¡Pero eso es el comunismo, el "irrealizable" comunismo! Sin embargo, los individuos de las clases dominantes que son lo bastante inteligentes para darse cuenta de la imposibilidad de que el actual sistema continúe -y no son pocos - se han erigido en los apóstoles molestos y chillones de la producción cooperativa. Ahora bien, si la producción cooperativa ha 
de ser algo más que una impostura y un engaño; si ha de sustituir al sistema capitalista; si las sociedades cooperativas unidas han de regular la producción nacional con arreglo a un plan común, tomándola bajo su control y poniendo fin a la constante anarquía y a las convulsiones periódicas, consecuencias inevitables de la producción capitalista, ¿qué será eso entonces, caballeros, más que comunismo, comunismo "realizable"?" Marx, 2012:32).

Este uso de la noción de comuna implica su equiparación con la forma realizable de comunismo, es decir, con la evidencia política empírica de superación de las formas productivas del capitalismo. Marx propone un carácter corporativo, en donde la comuna más que un ente parlamentario es una corporación de trabajo: ejecutiva y legislativa al mismo tiempo. Marx la considera el primer ejemplo concreto de "dictadura del proletariado". Esta rebelión fue sometida con gran dureza casi de inmediato. Después de un mes de combates que culminaron en la llamada semaine sanglante (semana sangrienta), desde el 21 al 28 de mayo, la comuna perdió el control de la ciudad. El balance final supuso unos 10.000 muertos, el destrozo de más de 200 edificios y monumentos, y el sometimiento de París a la ley marcial durante cinco años.

En sentido similar, los autores chinos Chin Li y Chie-Yun (2012) en su texto "¿Cómo es la comuna popular?", publicado en el marco de la Revolución Cultural China, utilizan la noción de comuna en el contexto asiático y durante el siglo XX. Definen a la comuna popular cómo "la mejor forma de organización para la consecución del socialismo y para la gradual transición al comunismo, y se desarrollará para convertirse en una unidad básica en la futura sociedad comunista" (Chin Li y Chie-Yun,
2012:55).

Estos autores indican algunos elementos a considerar, en primer lugar se refieren a los "cuadros directivos" (trabajadores del partido comunista y del gobierno chino) como comprometidos con "mejorar las condiciones de la comuna y aplicar la línea política del presidente Mao-Tse-tung" (Chin Li y Chie-Yun, 2012:10). Así mismo, expresan cómo "para el presidente Mao era conveniente establecer comunas populares en los campos de China" (Chin Li y Chie-Yun, 2012:10).

La comuna china tiene entre sus ventajas combinar la industria, la agricultura, el comercio, la cultura y la educación, y el ejército. Así mismo, su organización se da bajo una línea política correcta, una línea socialista, permitiendo el desarrollo y el fortalecimiento de una economía planificada.

La Comuna no sólo administra la producción agrícola, ganadera, pesquera, de la silvicultura y de las operaciones secundarias, sino que ejerce el poder del anterior gobierno para administrar la industria, el comercio, la cultura y educación, la sanidad, asuntos civiles, y seguridad pública. El gobierno ya dejó de existir y es reemplazado por la Comuna, por esto, la Comuna es tanto una organización económica colectiva como una entidad básica del Poder socialista de China en el campo. O sea, una organización que fusiona en sí el Poder de base y la administración económica (Chin Li y Chie-Yun, 2012).

En este texto, los autores presentan una anécdota sobre "tendencias revisionistas" dentro de la Comuna de Liutien:

"En la aldea, un campesino medio que sabía de albañilería, casi no participaba en el trabajo colectivo y para ganar más trabajaba afuera como 
jornalero. Lo cual es, en realidad, un trabajo individual. Criaba además, individualmente, un burro y un burrito. Vendió el último en la feria a buen precio. Estos hechos constituyen una acción que se aparta del campo de la economía colectiva y desarrolla espontáneamente la economía capitalista. Con el dinero ganado construyó una casa, la más elegante de la aldea, para vanagloriarse frente a la economía colectiva. Los terratenientes y campesinos ricos le felicitaban secretamente. Así surgió un rumor frío en los rincones oscuros: 'El que no participa en el trabajo colectivo gana más'" (Chin Li y Chie-Yun, 2012:27).

Los autores continúan con la anécdota:

"Se llevó a cabo la rectificación del estilo de trabajo en la célula del Partido y se esclareció la orientación de la lucha. Se movilizó a los comuneros para asestar duros golpes a las actividades destructivas de los enemigos de clase y se criticaron seriamente las corrientes perniciosas del capitalismo. De esta manera educaron a los comuneros y ayudaron a un reducido número de ellos que se había apartado de la vía de la colectivización volver al camino correcto" (Chin Li y Chie-Yun, 2012:29).

Los anteriores elementos nos permiten ver algunas posiciones de interés, la primera es ver la comuna como producto de gobierno y de una línea de un partido político, más allá de la organización de los actores interesados responde a la línea político-económica de una administración gubernamental. Al mismo tiempo, se define la comuna como un ente socialista y comunista, es decir, responde justamente a criterios político-ideológicos definidos. Igualmente, bajo estos criterios la comuna tiene el deber, otorgado por el poder político gubernamental, de llevar a cabo "rectificaciones" en su territorio sobre actores que se desvíen del "camino correcto". Por último, esta noción de comuna, además de representar una organización de gran tamaño que implica la función en sí del Poder de base y la administración económica, reconoce otros elementos a trabajar como la cultura, la educación, y los asuntos civiles.

Con trabajar la cultura, se puede evidenciar el interés, al igual que en la comuna francesa, de intervenir las identidades de la población de modo que lo cultural es visto como un elemento indispensable para la transformación y control de la sociedad.

Es importante mencionar que de la China descrita en el texto a la China contemporánea muchas cosas han cambiado. En la actualidad, aunque la sociedad china no goza de las mayores libertades y sigue existiendo represiones contra el campesinado, la sociedad urbana china tienen amplitud en sus políticas culturales y económicas, convirtiéndose en el siglo XXI en la primera economía mundial.

En el caso de América Latina, la noción de Comuna ha sido colocada en la palestra en Venezuela a partir de las políticas públicas desde hace algunos años. En este sentido, se hace necesario recorrer teórica e históricamente esta noción en el país sudamericano más allá de los debates políticos e ideológicos que pueda despertar esta discusión, el interés de esta investigación es conocer las distintas perspectivas del uso de esta noción, por tanto, el antecedente venezolano por tratarse de un ejemplo reciente y de actualidad resulta de sumo interés para los objetivos del mismo.

Algunos autores como Tapia (2012) hablan de comuneros durante el período colonial en Venezuela. En su texto Los comuneros de Mérida, narra cómo producto del aumento de los impuestos al tabaco y al aguardiente, y la imposición 
de nuevas restricciones comerciales por parte de la Corona Española, se desata un movimiento rebelde en gran parte de la región andina en 1781 . Inicia en la Villa del Socorro, localidad perteneciente al Reino de la Nueva Granada.

Este movimiento invade múltiples esferas del tejido social colonial. Los participantes de esta revuelta eran los llamados "gente de color", dando cuenta que los eventos subversivos fueron desencadenados por un grupo social particular, cuya posición no era la más favorable. En la medida en que la revuelta fue cobrando forma, se unirían sujetos de otros grupos sociales que, en circunstancias menos agitadas, pertenecían a grupos más privilegiados (Tapia, 2012).

Estos grupos admitían su adhesión al Rey, pero protestaban. Lo que parece paradójico se traduce en la reivindicación de la figura del Rey como una imagen representativa y legitimadora del sistema imperante. El monarca era equivalente a legalidad, la cual no oprimía a los subalternos, sino que restringía la libertad de acción de las autoridades coloniales.

"En tal sentido, la presencia de esta figura autoritaria abstracta en la rebelión era una forma de darle legitimidad, por medio de la evocación de la figura que limitaba el rango de acción de los representantes de las instituciones coloniales" (Tapia, 2012:23).

Desde el punto de vista de los insurrectos se pensaba que las medidas habían sido tomadas sin el consentimiento del Rey, pues se llegó a decir que si éste llegase a saber sobre las miserias a las que les exponían las autoridades regionales, se les mandaría "a cortar la cabeza a quienes sin méritos se intitulaban fieles vasallos" (Tapia, 2012:34).
La posibilidad de que se construyese una identidad común entre los blancos propietarios, los campesinos, los indígenas y la "gente de color" estuvo relacionada con una intensificación de la represión del sistema; que llegó al punto en que los sujetos pertenecientes a los grupos privilegiados tuviesen una vivencia que los identificó con aquellos que, históricamente, se encontraban en la situación menos ventajosa. Aunque desde los puntos de vista locales de los dirigentes de la rebelión no estaba claro que el horizonte de un movimiento como ese era contradictorio con la referencia a la imagen del Rey, sí estaba presente, en cambio, la necesidad de establecer distancia y diferencias con las políticas de los agentes que representaban al sistema (Tapia, 2012). Se puede ver cómo la construcción identitaria está directamente relacionada con la representación de los contrastes de las figuras de poder.

El autor nunca deja claro si el movimiento se autodenominaba "comuneros" o hablaban de "comuna", pero lo cierto es que él se refiere a ellos como tal, y constituye de esta manera un antecedente -tal vez forzado- de "lo comunal" en Venezuela. Se puede reconocer que esta rebelión nunca se planteó la toma del poder ni subvertir el orden establecido, sin embargo el autor esgrime que en la revuelta "comunera" estaba presente no sólo la idea de autonomía frente al régimen colonial, sino también la conformación de un orden económico y político sobre la base de la propiedad colectiva. Alega, además, que "este tipo de propiedad tuvo sus orígenes históricos a partir de la fusión entre las imposiciones del capitalismo agrario y las tradiciones culturales indígenas" (Tapia, 2012:39).

Más allá de las precisiones 
históricas, se puede evidenciar en el uso de esta noción de comuna varias particularidades. En primer lugar, hace un llamado a "tomar conciencia" del orden económico y político del orden colonial y del rol que estos grupos subalternos juegan en el mantenimiento de dicho orden. En segundo término, los Ilamados "comuneros de Los Andes" evidencian cómo los tejidos sociales de todo sistema son capaces de rearticularse para configurar sentidos de pertenencia y de solidaridad entre los grupos, lo que le otorga a los sujetos capacidad transformadora de la realidad y las estructuras. Por último, este uso de la noción de comuna permite vislumbrar un carácter reivindicativo de la comuna, sin necesariamente ser organizaciones contradictorias con el orden de fondo.

Volviendo al presente, la Comuna en Venezuela se trata de un espacio político-administrativo en donde, siguiendo las normativas y legislaciones pertinentes, grupos de familias $y$ comunidades pueden organizarse para alcanzar la conformación de estas figuras de gestión pública, las cuales tienen entre sus competencias elaborar, ejecutar y controlar la administración de proyectos y recursos de propiedad social.

Una vez revisados diversos antecedentes y perspectivas del uso y la noción de Comuna alrededor de distintas épocas y distintos lugares del mundo, resulta pertinente conducir la reflexión sobre qué es la noción de comuna y cuáles son los usos de la misma.

\section{4. ¿Qué es la comuna?}

Como se ha visto a lo largo de su desarrollo histórico la noción de comuna ha hecho referencia a formas de organización política con ciertas características en común, aunque no por eso, salvadas de discrepancias y heterogeneidades.

La comuna medieval italiana se caracterizaba por sus funciones político-administrativas, su carácter de reorganización territorial y la posibilidad de creación de formas novedosas de reproducción de la vida económica y productiva. En este sentido, representaba un espacio de distinción y diferenciación del régimen feudal predominante. De hecho, en estas comunas medievales nacieron las primeras formas de producción capitalistas y de acumulación de riquezas de la burguesía que a posteriori se convertiría en el motor del desarrollo industrial y daría nacimiento al capitalismo.

Por otro lado, en marzo de 1871 se produjo en París la revuelta social que dio origen a la llamada Comuna de París. A pesar de sólo durar dos meses, esta experiencia tuvo enormes repercusiones sobre la ciudad y las formas de organizar la ciudad moderna en una época en donde se planteaban alternativas a la creciente industrialización y el desarrollo del capitalismo (Laskowski, 2011).

Del mismo modo, la Comuna de París tuvo ese espíritu de resistencia, en este caso, se presentaba como una alternativa a la sociedad monárquica y las formas tradicionales de división social. Además, también fueron creados a lo largo de los distintos barrios parisinos los Comités Republicanos de Vigilancia, los cuáles suplantaban las funciones de la policía central, exigiendo las elecciones por sufragio de todas las autoridades, acompañaban la apropiación comunal de víveres y su distribución, así como, la defensa militar de la comuna ante Prusia.

Este antecedente marcó un precedente histórico, como señala 
Laskowski (2011), pues significa el primer antecedente de gobierno obrero de la historia, representando un nuevo tipo de Estado y sus connotaciones en relación con la propiedad privada y las nuevas formas de relación social.

Entre las características más importantes destacan (Laskowski, 2011) que su formación fue resultado de la voluntad asociativa de distintos sectores de los ciudadanos franceses, como forma espontánea de organización local, encaminada en un bien común: la conquista efectiva de la igualdad en las condiciones de vida humana.

Otra experiencia de interés es la mencionada comuna china. Considerando que China era un país con bajo nivel de desarrollo, una vez instaurada la revolución, las principales políticas de transformación económica giraron entorno hacia el crecimiento agrícola. El gobierno chino inició la reforma agrícola a principios de los 80 , aplicando en método conocido como "sistema de responsabilidad en la producción mediante contrato familiar con ingresos en función del rendimiento", en el cual se establecían contratos entre las familias y las autoridades locales (Sornoza et al. 2018).

A estas familias, se atribuía el derecho de uso de determinadas parcelas, resultantes de la división de las tierras agrícolas comunales, proporcionalmente al número de familias; especificando las cuotas a pagar al estado y habilitando la posibilidad de que cualquier excedente pueda ser libremente vendido en mercados en expansión.

En este sentido, como se menciona anteriormente, la comuna china representó una forma de control político-administrativo gubernamental, tratándose de una línea política de partido a través de cual se ejecutaban las políticas económicas del Estado. La comuna china concebía el EstadoPartido-Gobierno-Familia como una misma unidad de trabajo y control social.

Como último ejemplo, se aborda la noción de comuna popularizada en Venezuela desde principios de este siglo. Los aportes de la profesora María León Álvarez (2013) evidencian que a través de diversos mecanismos legislativos y ejecutivos se ha impuesto en el país un ejercicio de soberanía a través del llamado "poder popular", es decir, a través de grupos políticos organizados.

De este modo, Centro Gumilla (2009), Goldfrank (2011), Sánchez y Rodríguez (2012) y León (2013) señalan que existe un desfase entre el texto constitucional vigente, y el ordenamiento jurídico mencionado. Asímismo, en alusión a la división político-territorial de estados y municipios, los textos legales se ubican a la par de remisiones de un nuevo modelo de sociedad socialista y comunal. Igualmente, al indicar que toda organización debe incorporarse a los comités de trabajo de la comuna, vulnera el derecho de libre participación y de asociación de los venezolanos. Los autores coinciden que los consejos comunales y las comunas, lejos de ser Poder Originario, son instancias de participación registradas ante el gobierno con el fin de cumplir los lineamientos político-ideológicos del gobierno nacional.

En este sentido, Harnecker (2010) y Mata (2015), sostienen que el régimen comunal permite el fortalecimiento del Estado, vislumbrando las comunas como una nueva forma de descentralización y redistribución del poder. Sostiene que una de las ideas más revolucionarias del gobierno venezolano fue la creación de estas figuras político-administrativas 
inéditas en el resto de América Latina, buscando favorecer la participación ciudadana de las familias.

Entre las funciones de estas figuras en Venezuela está el seguimiento, control y ejecución de políticas públicas y proyecto de desarrollo local (Mata, 2015). Sin embargo, siempre destacan el carácter socialistas de las mismas, así como su construcción como instrumento de superación del modelo capitalista y las bases de la construcción del socialismo (Yanes, 2014).

López (2018) en contraparte afirma que las comunas son prácticas impuestas desde arriba hacia abajo, que reducen y partidizan el pluralismo comunitario, lo cual limita su potencial autonómico y propicia su cooptación.

Sostiene, además, que las comunas en Venezuela, como parte de un repertorio de innovaciones participativas, en un contexto democrático que los deslindara de los partidos políticos o del Estado, podrían constituirse en espacios para el desarrollo de igualdad, corresponsabilidad, solidaridad y alternativas productivas de trabajo colectivo, y propiciar la ciudadanía, el empoderamiento y demás atributos que la bibliografía especializada asocia al ejercicio de la participación directa sin mediaciones políticas. Sin embargo, en las actuales circunstancias, este tipo de instituciones enfrentan insalvables obstáculos y más bien tenderán a desintegrarse o a quedar como meras correas de distribución de bienes que otorga el gobierno a cambio de lealtades políticas.

\section{Reflexiones finales}

Existen múltiples definiciones de comuna, se trata de un concepto múltiple, diverso y ambiguo. A partir de nuestro recorrido teórico hemos podido identificar dos grandes nociones de la categoría de comuna. Por un lado, la que refiere a una organización políticoadministrativa local con funciones específicas de control y gestión de políticas públicas.

En otro sentido, aunque no antagónico, se ubica la noción de comuna como una forma organizativa de resistencia política, en primer momento anti-feudal y posteriormente anticapitalista (hasta la actualidad).

Lo anterior ubica al concepto en una situación liminal, por un lado, se trata de organizaciones que responden al orden institucional y responden a esa institucionalidad (caso comunas en América Latina, caso Venezuela, caso China), pero, por otro lado, también la noción refiere organizaciones distintas o autónomas al orden institucional y que buscan reformarlo (noción marxista).

De este modo, en el caso de Venezuela, el recorrido teórico emprendido arroja que las llamadas comunas venezolanas tienen similitudes con las comunas chinas del siglo $\mathrm{XX}$ en tanto: 1) son propuestas del Estadonación; y 2) responden y reproducen la ideología oficial del gobierno.

En este mismo sentido, no podemos comparar las actuales Comunas venezolanas con las comunas descritas por Francisco Tapia, en tanto las primeras son producto de procesos direccionados desde el Estado-Nación y no producto de dinámicas internas de los grupos, como el caso de las descritas por Tapia.

En términos generales, la comuna es teóricamente una organización política diferenciada de partidos políticos, es gestor de políticas públicas. Es una construcción socio-cultural, por tanto, territorial, sobre un espacio delimitado. 
Este espacio trasgrede (usualmente) las fronteras político-administrativas establecidas, la Comuna implica así nuevas fronteras administrativas y nuevas formas de gerencia. Lo anterior no aplica a la noción de comuna como forma básica de la administración en varios países de América Latina y el mundo. Aplica sí, paradójicamente, a las Comunas como formas de resistencia, aún cuando sean originadas desde el propio Estado.

La noción de comuna, como toda categoría del mundo social, es polivalente y de carácter multidimensional. Resulta imposible comprenderla y analizarla sin la experiencia vivida del campo, la cual en termino final, da sentido específico a la multiplicidad de acepciones y posibilidades que arropan a este concepto desde hace siglos, desde los distintos rincones del mundo y las diversas experiencias históricas.

Por último, es importante destacar cómo las nuevas tendencias del desarrollo hacen hincapié en las formas de participación de la sociedad civil organizada en el diseño de las políticas públicas que proponen los gobiernos nacionales en los espacios locales. Para ello, existe una corresponsabilidad entre instituciones gubernamentales y sociedad civil en la elaboración de las políticas públicas, que buscan la consolidación de nuevos escenarios de discusión y participación, los cuales intentan reforzar los valores de la vida pública y civilidad. Sin embargo, la toma de decisiones de las comunidades locales está, por lo general, condicionada por las políticas institucionales y los aparatos gubernamentales que establecen los criterios en los cuales la sociedad civil debe participar.

\section{Referencias bibliográficas}

Bobbio, N., y Mateucci, N. (1985). Diccionario de política. 4ta. ed. Siglo $\mathrm{XXI}$ editores.

Centro Gumilla (2009). Estudio sobre los Consejos Comunales de Venezuela. http://gumilla. org/?p=page\&id=1217966587

Chin, L., y Chie-Yun, T. (2012) La comuna de Chiliying. Extracto del libro ¿Cómo es la comuna popular?. 2da. Ed. Editorial La Estrella Roja. https:// web.ua.es/es/giecryal/documentos/ otrosdocs/docs/comuna-popularchina.pdf

Goldfrank, B., (2011). Los Consejos Comunales: ¿Avance o retroceso para la democracia venezolana? Íconos, (40), 41-55. https://doi. org/10.17141/iconos.40.2011.445

Harnecker, M. (2010). América Latina y el socialismo del siglo $X X I$. Al Aire Libro Ediciones. http://biblioteca.clacso.edu.ar/ Chile/inedh/20161214062259/ socialismosxxiMH.pdf

Laskowski, M. C. (2011). La Comuna de París: Inspiración y fundamento de la ciudad; Instituto de Desarrollo Económico y Social. Prácticas de Oficio, (7-8), 1-12. https://ri.conicet. gov.ar/handle/11336/70208

León, M. (2013). Soberanía y consejos comunales. Frónesis, 20(1), 52 - 62.

López, M. (2018) Socialismo y comunas en Venezuela. Nueva Sociedad, (274). https://dialnet.unirioja.es/ servlet/articulo?codigo $=6408897$

Marx, C. (2012). La comuna de París. Extracto de La guerra civil en Francia. 2da. ed. Editorial La Estrella Roja.

Marx, K., y Engels, F. (1848). Manifiesto del Partido Comunista. https://www. marxists.org/espanol/m-e/1840s/48- 
Flores Arocutipa, Javier Pedro; Tarmeño Bernuy, Luis Edgar; Cruz Montero, Juana María; Franco Medina, Jorge Lázaro

Discusión de la noción de comuna. Recorrido teórico-documental

\section{manif.htm}

Mata, M. (2015). Las comunas en el sistema político venezolano. Revista de Derecho UNED, (17). https://dialnet.unirioja.es/servlet/ articulo?codigo $=5423959$

Sánchez, N., y Rodríguez López, J. (2012). Valoración de la participación social y su relación con estratos socioeconómicos y residencia en zona capital en el Estado Zulia, Venezuela. Espacio Abierto, 21(4), 775-800. https:// produccioncientificaluz.org/index. php/espacio/article/view/1761
Sornoza, G., Parrales, M., Sornoza, D., y Guaranda, V. (2018). Reforma económica China: de economía planificada a economía de mercado. Revista Venezolana de Gerencia (RVG), 23(83), 521-529.

Tapia, F. (2012). Los comuneros de Mérida. 2da. Ed. Editorial la Estrella Roja.

Yanes, T. (2014). Participación comunitaria en el consejo comunal Callao Sector 4. Municipio San Francisco, estado Zulia, Venezuela. Interacción y Perspectiva. Revista de Trabajo Social, 4(1), 48-70. https://dialnet.unirioja.es/servlet/ articulo?codigo $=5154923$ 